\title{
PENERAPAN FUNGSI MANAJEMEN KELOMPOK TANI JAGUNG DI DESA LEMBEAN
}

\author{
Obeth Fakdawer \\ Melsje Y. Memah \\ Lorraine W. Th. Sondakh
}

\begin{abstract}
The purposes of this research are: (1) To Identify Application of Management Function of Maize Farmer Group in Lembean Village and (2) Analyze Application of Management Function of Maize Farmer Group In Lembean Village. This research was conducted for 5 months from February to June 2017 and located in Lembean Village, Sub-district Kauditan, North Minahasa Regenct, North Sulawesi Province. The data used in this research is Primary and Secondary data. Primary data obtained through observation in the field and directly interviews. Interviews were conducted with farmer groups related to farmer group activities to find out the description of the implementation of management functions undertaken by farmer groups. In addition, researchers also conducted interviews with maize farmers and collectors to determine the current condition of maize prices and the flow of maize seeds from farmers to suppliers. Secondary data is obtained from relevant literature, as well as documents and reports owned by farmer groups and related agencies. This study focuses on the management of material flow as well as the flow of information from the implementation of the management function of maize farmer groups in Lembean. The results of the observations and interviews were analyzed by descriptive analysis method. The result of the research shows that the implementation of the management function in the maize farming group in the sub-district of Kauditan, with management functions measured and obtained in Lembean maize farmer group, Tumaratak maize farmer group and maize farming group Waleposan implementation of management function on the implementation and evaluation well in research this is in very high category whereas for the Implementation of Management Function Planning And Function Management Monitoring is on high category, on the three groups of maize farmers in Lembean village.
\end{abstract}

Keywords: implementation, management functions, farmer groups, maize, Lembean Village

\section{ABSTRAK}

Tujuan dari penelitian ini yaitu: (1) Mengidentifikasi Penerapan Fungsi Manajemen Kelompok Tani Jagung Di Desa Lembean dan (2) Menganalisis Penerapan Fungsi Manajemen Kelompok Tani Jagung Di Desa Lembean. Penelitian ini dilaksanakan selama 5 bulan yaitu dari bulan Febuari sampai bulan Juni 2017 dan berlokasi di Desa Lembean Kecamatan Kauditan Kabupate Minahasa Utara, di Sulawesi Utara. Data yang digunakan dalam penelitan ini adalah data Primer dan Sekunder. Data primer didapat melalui pengamatan di lapangan serta wawancara secara langsung. Wawancara dilakukan dengan pihak kelompok tani terkait kegiatan kelompok tani untuk mengetahui gambaran penerapan fungsi manajemen yang dilakukan oleh kelompok tani. Selain itu, peneliti juga melakukan wawancara dengan petani jagung serta pengumpul untuk mengetahui kondisi harga jagung terkini serta alur bibit jagung dari petani ke supplier. Data sekunder diperoleh dari literatur yang relevan, serta dokumen dan laporan yang dimiliki oleh kelompok tani dan instansi terkait. Penelitian ini berfokus pada pengelolaan aliran material serta aliran informasi dari penerapan fungsi manajemen kelompok tani jagung di Lembean. Hasil dari observasi dan wawancara dianalisis dengan metode analisis deskriptif. Hasil penelitian menunjukkan Penerapan fungsi manajemen pada kelompok tani jagung di Desa Lembean kecamatan kauditan, dengan fungsi manajemen yang di ukur dan diperoleh dalam kelompok tani jagung Lembean, kelompok tani jagung Tumaratak dan kelompok tani jagung Waleposan penerapan fungsi manajemen pada pelaksanaan dan evaluasi dengan baik dalam penelitian ini pada kategori sangat tinggi sedangkan untuk Penerapan Fungsi Manajemen Perencanaan Dan Fungsi Manajemen Monitoring ada pada kategori tinggi, pada ketiga kelompok tani jagung di Desa Lembean.

Kata kunci: penerapan, fungsi manajemen, kelompok tani, jagung, Desa Lembean 


\section{PENDAHULUAN}

\section{Latar Belakang}

Peranan sektor pertanian dalam perekonomian nasioal sangat penting dan strategis. Hal ini terutama karena sektor pertanian masih memberikan lapang kerja bagi sebagian besar penduduk yang ada dipedesaan dan menyediakan bahan pangan bagi penduduk. Semua usaha pertanian pada dasarnya adalah kegiatan ekonomi sehingga memerlukan dasardasar pengetahuan yang sama akan pengelolaan tempat usaha, pemilihan benih/bibit, metode budidaya, pengumpulan hasil, distribusi produk, pengelolahan, pengemasan produk, dan pemasaran. Besarnya penduduk yang terlibat dalam sektor pertanian serta kemampuannya dalam menghadapi krisis ekonomi yang terjadi saat ini juga merupakan alasan lain sektor pertanian sangat penting untuk dipertahankan dalam pelaksanaan pembangunan nasional di Indonesia (Sadono 2008). Manajemen adalah suatu proses atau kerangka kerja yang melibatkan bimbingan atau pengarahan terhadap suatu kelompok orang kearah tujuan organisasional atau maksud - maksud yang nyata, Artinya perlu diberikan bimbingan karena tidak semua terampil dalam melaksanakan kegiatan organisasi. Cara yang digunakan untuk membimbing bergantung pada kebijakan dan keinginan pemimpin, seperti pekerja yang kurang terampil diberikan pelatihan untuk meningkatkan kemampuannya (Terry dan Rue 2009). Organisasi /kelompok tani himpunan atau kesatuan masyarakat petani yang hidup dan tinggal bersama dalam satu lingkungan social, sehingga menimbulkan hubungan timbal balik dan saling menpengaruhi serta memiliki kesadaran untuk salingtolong menolong (Mardikanto dalam Mariani 2012). Nuryanti dan Swastika (2011) menjelaskan bahwa secara umum, kelompok tani dibentuk untuk memecahkan permasalahan yang dihadapi kelompok tani yang tidak bisa diatasi secara individu, kelompok tani dapat dibentuk secara swadaya maupun atas dasar kepentingan kebijakan dari pemerintah melalui dinas pertanian, untuk itulah petani perlu kelompok. Sulawesi Utara merupakan salah satu provinsi di Indonesia yang memiliki sumberdaya alam yang potensial didalamnya termasuk sektor pertanian.Kontribusi sektor pertanian terhadap perekonomian daerah masih tergolong tinggi. Oleh karena itu, jagung merupakan komoditas yang mempunyai nilai strategis seperti halnya beras (Anonim, 2002). Desa Lembean sebagai salah satu Desa di Kabupaten Minahasa Utara yang terus berupaya untuk pengembangan tanaman jagung, petani jagung di Minahasa Utara memiliki kedudukan strategis dalam ketahanan pangan. Manajemen kelompok tani akan semakin meningkat apabila dapat menumbuhkan kekuatankekuatan yang dimiliki dalam kelompok itu sendiri untuk dapat menggerakkan dan mendorong perilaku anggotanya ke arah pencapaian tujuan kelompok, sehingga kelompok tani tersebut akan berkembang menjadi lebih dinamis. Agar kelompok tani dapat berkembang secara dinamis, maka harus didukung oleh seluruh kegiatan yang meliputi inisiatif, daya kreasi dan tindakan-tindakan nyata yang dilakukan oleh pengurus dan anggota kelompok tani dalam melaksanakan rencana kerja anggota kelompok yang telah disepakati bersama. Pada dasarnyadinamika anggota kelompok tani merupakan gerakan bersama yang dilakukan oleh anggota kelompok tani secara serentak dan bersamaan dalam melaksanakan seluruh kegiatan anggota kelompok tani dalam mencapai tujuannya, yaitu peningkatan hasil produksi dan mutunya yang pada gilirannya akan meningkatkan pendapatan mereka menurut (Suhardiyono,1992). Kelompok petani adalah produsen dan petani juga sekaligus kelompok konsumen terbesar yang sebagian masih miskin dan membutuhkan daya beli yang cukup untuk membeli pangan. kelompok petani jagung harus memiliki kemampuan untuk memproduksi pangan sekaligus juga harus memiliki pendapatan yang cukup untuk memenuhi kebutuhan pangan mereka sendiri. Perlu sekali partisipasi pemerintah Sulawesi Utara dalam melakukan pemberdayaan kelompok tani jagung Dikabupaten Minahasa Utara kuhusnya di Desa Lembean.

\section{Rumusan Masalah}

Berdasarkan latar belakang masalah yang dikemukakan di atas maka yang menjadi permasalahan: Bagaimana penerapan fungsi manajemen dalam kelompok tani di Desa Lembean.

\section{Tujuan Penelitian}

Untuk mengetahui penerapan fungsi manajemen dalam kelompok tani jagung di 
Desa Lembean, Kecamatan Kauditan, Kabupaten Minahasa Utara.

\section{Manfaat Penelitian}

1. Bagi petani sebagai pelaku utama. Hasil penelitian ini diharapkan dapat digunakan sebagai informasi dan bahan pertimbangan di Desa Lembean.

2. Penelitian ini diharapkan bermanfaat bagi upaya meningkatkan manajemen dalam kelompok tani serta memberikan informasi bagi pihak yang membutuhkan informasi sehubungan dengan penelitian.

3. Bagi pihak yang berkompeten diharapkan dapat menjadi informasi dalam membangun koordinasi yang harmonis dalam penerapan fungsi manajemen dalam kelompok tani jagung di Desa Lembean.

\section{METODOLOGI PENELITIAN}

\section{Waktu dan Tempat Penelitian}

Penelitian ini dilakukan di Kabupaten Minahasa Utara. Penelitian ini dilakukan selama beberapa bulan, yaitu Februari sampai Juni 2017. Hal ini dimanfaatkan penelitian agar berfokus melaksanakannya dalam waktu yang seefisien mungkin.

\section{Jenis dan Sumber Data}

Jenis dan sumber data yang dipakai dalam penelitian ini sebagai berikut:

1. Data primer diperoleh melalui wawancara langsung kepada responden dengan menggunakan kuesioner yang telah disiapkan oleh peneliti

2. Data sekunder diperoleh melalui Kantor Pertanian/Kantor Desa tempat penelitih (Instansi terkait).

\section{Metode Pengambilan Sampel}

Populasi kelompok tani jagung di Desa Lembean, Kecamatan Kauditan, Kabupaten Minahasa Utara ada 14 kelompok tani, pengambilan sampel secara proposif sampling tiga (3) kelompok tani yang aktif mengusahakan tanaman jagung.

\section{Metode Pengumpulan Data}

Metode pengambilan data secara survei dan kuesioner kepada 3 kelompok tani jagung di Desa Lembean yang berjumlah 30 petani jagung setiap kelompok 10 petani. Variabel dalam penelitian ini untuk mengukur karakteristik responden sebagai berikut:

1. Perencanan (skoring)

2. Pelaksanan (skoring)

3. Monitoring (skoring)

4. Evaluasi (skoring)

\section{Konsep Pengukuran Variabel}

Variabel-variabel yang dikaji dalam penelitian ini adalah :

1. Karakteristik Responden, mencakup

a) Umur, yaitu umur, kelompok tani jagung dinyatakan dalam tahun.

b) Tingkat Pendidikan, dilihat dari pendidikan terakhir yang ditempuh responden diukur dalam tahun.

c) Penelitian ini merumuskan, dilihat dari penerapan kelompok tani jagung, yaitu: Kelompok tani jagung, pengukuran dilakukan dengan menggunakan skor dilihat dari variabel dalam penelitian ini untuk mengukur karakteristik responden sebagai berikut:
1. Perencanan
(skoring)
2. Pelaksanan
(skoring)
3. Monitoring
(skoring)
4. Evaluasi
(skoring)

\section{Analisis Data}

Penelitian ini menggunakan metode analisis data, yaitu metode analisis deskriptif. Metode analisis deskriptif adalah metode penelitian yang melibatkan analisis data berupa deskriptif dan data tersebut tidak secara langsung dapat dikuantifikasi. Analisis deskriptif merupakan metode pencarian fakta dengan interpretasi yang tepat mengenai masalah-masalah yang ada dalam masyarakat, tata cara yang berlaku, serta situasi-situasi tertentu termasuk tentang hubungan, kegiatan, sikap, pandangan, serta proses yang sedang berlangsung dan pengaruh dari suatu fenomena. Dengan menggunakan analisis deskriptif ini maka akan diperoleh gambaran mengenai penerapan fungsi manajemen dalam kelompok 
tani jagung. Untuk mengetahui penerapan fungsi manajemen dalam kelompok tani jagung. Analisis data dalam penelitian ini adalah deskriptif dengan menggunakan daftar tabel dan angka. Untuk mengukur penerapan fungsi manajemen disusun 10 pernyataan dengan total responden yaitu 3 kelompok. Setiap jawaban dihubungkan dengan bentuk pernyataan atau dukungan yang diungkapkan dengan kata-kata berikut:

$\begin{array}{ll}\text { Sangat Tinggi } & \text { Skor 5 } \\ \text { Tinggi. } & \text { Skor 3 } \\ \text { Sedang. } & \text { Skor 1 } \\ \text { Rendah. } & \text { Skor 0 }\end{array}$

Dengan cara perhitungan skor masing-masing pernyataan. Jumlah Skor Tiap Kriterium= Capaian Skor x Jumlah Responden:

$$
\begin{aligned}
& \mathrm{S}_{5}=1 \times 5 \times 5=25 \\
& \mathrm{~S}_{3}=3 \times 5 \times 5=15 \\
& \mathrm{~S}_{1}=1 \times 5 \times 5=5 \\
& \mathrm{~S}_{0}=0 \times 5 \times 5=0
\end{aligned}
$$

Jumlah skor tinggi untuk siap pernyataan (Skor Tertinggi) $=25$

Jumlah skor terendah $=0$

Dengan Interpretasi nilai:

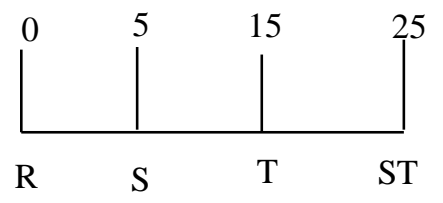

Cara perhitungan skor keseluruhan untuk mengetahui: penerapan fungsi manajemen. Jumlah Skor Seluruh Kriterium = Capaian Jumlah Skor x Jumlah Responden x Instrument pernyataan

Untuk :

$$
\begin{aligned}
& \mathrm{S}_{5}=5 \times 10 \times 5=250 \\
& \mathrm{~S}_{3}=3 \times 10 \times 5=150 \\
& \mathrm{~S}_{1}=1 \times 10 \times 5=50 \\
& \mathrm{~S}_{0}=0 \times 10 \times 5=0
\end{aligned}
$$

Jumlah skor tinggi untuk keseluruhan pernyataan $=250$ (Tertinggi)

Jumlah skor terendah $=0$ (Rendah)

Dengan Interpretasi nilai :

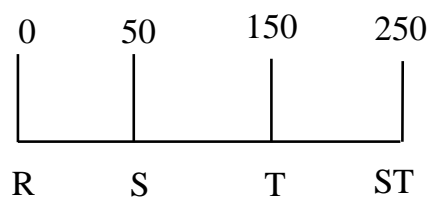

\section{HASIL DAN PEMBAHASAN}

\section{Gambaran Umum Wilayah Penelitian}

Tentang Desa Lembean berbujur menajang dari arah barat ketimur $15 \mathrm{TU}$ dengan kemiringan $5^{\circ}$ suhu udara minimum $22^{\circ}$ dalam maximum $30^{\circ}$. tinggi dari permukaan laut kurang lebih 270 meter, secara umum iklim tropis curah hujan 3000 $\mathrm{M} / \mathrm{Th}$. Desa Lembean berbatasan sebelah utara gunung klabat, makin ke utara makin menanjak sampai pada yang ditentukan, untuk perkebunan rakyakat selatan menuju pengunugan lembean. Bagian utara berbatasaan dengan hutan lindung gunung klabat. Bagian timur berbatasan dengan desa kassar. Bagian selatan berbatasan dengan pengunungan lembean /kombi. Bagian barat berbatasan dengan desa paslaten dan desa tumalutun.

\section{Luas Wilayah Desa Lembean}

Persentase luas Desa Lembean terlihat pada tabel 1, dimana wilayah terluas adalah Perkebunan rakyat dan wilayah yang terkecil persentase luasnya adalah Sawah /empang.

Tabel 1. Luas Wilayah Desa Lembean, 2016

\begin{tabular}{llc}
\hline No & Desa & Luas $(\mathrm{Ha})$ \\
\hline 1. & Perkebunan rakyat & $320 \mathrm{Ha}$ \\
2. & Ladang/tegalan & $100 \mathrm{Ha}$ \\
3. & Sawah /empang & $50 \mathrm{Ha}$ \\
4. & Tanah kritis/tandus & $60 \mathrm{Ha}$ \\
5. & Luas pemukiman dalam desa & $54 \mathrm{Ha}$ \\
& & \\
6. & Lain-lain & $266 \mathrm{Ha}$ \\
\hline & Jumlah & $\mathbf{8 5 0} \mathbf{H a}$ \\
\hline
\end{tabular}

Sumber Data: Desa Lembean, 2016

Tabel 1 menujukkan bahwa luas wilayah menurut Desa Lembean adalah Perkebunan rakyat seluas $320(\mathrm{Ha})$, dan luas wilayah terendah adalah Sawah /empang seluas $50(\mathrm{Ha})$.

\section{Jumlah Penduduk Desa Lembean}

Persentase jumlah penduduk menurut Daerah jaga di Desa Lembean terlihat pada Tabel 2, dimana jumlah penduduk menurut Jaga adalah Jaga II dan Jaga V yang terkecil persentase jumlah penduduknya. 
Tabel 2. Jumlah Penduduk Menurut Daerah Jaga dan Jenis Kelamin

\begin{tabular}{|c|c|c|c|c|}
\hline$\overline{\text { No }}$ & Daerah Jaga & Laki-laki & Perumpuan & Jumlah \\
\hline 1. & Jaga I & 89 & 105 & 194 \\
\hline 2. & Jaga II & 105 & 119 & 254 \\
\hline 3. & Jaga III & 97 & 117 & 274 \\
\hline 4. & Jaga IV & 96 & 133 & 229 \\
\hline 5. & Jaga V & 86 & 94 & 180 \\
\hline 6. & Jaga VI & 89 & 100 & 189 \\
\hline & Jumlah & 562 & 668 & 1,320 \\
\hline
\end{tabular}

Tabel 2 menunjukkan bahwa jumlah penduduk menurut daerah jaga dan jenis kelamin, dan untuk perbandingan antara lakilaki dan perempuan. Berdasarkan Tabel 2 diketahui jumlah penduduk laki-laki adalah 562 jiwa dan penduduk perempuan 668 jiwa maka sebesar 668 Artinya pada tahun 2016 setiap 100 penduduk perempuan terdapat 562 penduduk laki-laki. Daerah Jaga Satu memiliki angka perbandingan, jaga III tertinggi yaitu sebesar 274 dan desa terendah adalah jaga $\mathrm{V}$ yaitu sebesar 180 .

\section{Jumlah Kepala Keluarga Menurut Daerah Jaga dan Pendidikan Tamat/Tidak}

Persentase jumlah kepala keluarga menurut dearah jaga dan pendidikan terlihat pada Tabel 3, dimana jumlah kepala keluarga menurut daerah jaga adalah jaga IV.

Tabel 3. Kepala Keluarga Desa Lembean

\begin{tabular}{lccccc}
\hline Desa & & SD & SMP & SMA & Sarjana \\
\hline Jaga I & L/P & $6 / 12$ & $4 / 2$ & $5 / 4$ & $7 / 7$ \\
Jaga II & L/P & $13 / 10$ & $12 / 13$ & $47 / 54$ & $13 / 31$ \\
Jaga III & L/P & $9 / 18$ & $8 / 19$ & $60 / 47$ & $4 / 5$ \\
Jaga IV & L/P & $10 / 13$ & $16 / 17$ & $47 / 64$ & $23 / 25$ \\
Jaga V & L/P & $12 / 15$ & $10 / 11$ & $46 / 43$ & $9 / 14$ \\
Jaga VI & L/P & $10 / 11$ & $11 / 10$ & $30 / 50$ & $28 / 14$ \\
\hline Jumlah & L/P & $\mathbf{6 0 / 7 9}$ & $\mathbf{6 1 / 7 2}$ & $\mathbf{2 3 5 / 2 6 2}$ & $\mathbf{8 4 / 9 4}$ \\
\hline Sumber: Desa Lembean, 2016
\end{tabular}

Tabel 3 menunjukan bahwa kepala keluarga menurut daerah jaga dan pendidikan tinggi yang ditamatkan, dimana kepala keluarga menurut desa adalah jaga IV jumlah sebesar 139 SD, 133 SMP, 497 SMA, dan 178 Sarjana

\section{Deskripsi Responden}

Responden yang digunakan dalam penelitian ini merupakan responden yang ditemui langsung di kelompok tani jagung di Desa Lembean. Hasil dari penyebaran kuesioner sebanyak 30 responden didapatkan karakteristik responden berdasarkan jenis kelamin, umur, dan tingkat pendidikan terakhir. Berikut dipaparkan hasil dari masing-masing karakteristik responden yang ditemui di kelompok tani jagung di Desa Lembean.

\section{Karakteristik Responden}

Berikut ini adalah deskripsi responden dalam penelitian ini berdasarkan jenis kelamin dapat dilihat pada Tabel 4.

Tabel 4. Karakteristik Responden Berdasarkan Jenis Kelamin/ Umur

\begin{tabular}{lcc}
\hline Jenis Kelamin & Jumlah & Presentase \\
Laki-laki & 20 & 67 \\
Perempuan & 10 & 33 \\
\hline Total & $\mathbf{3 0}$ & $\mathbf{1 0 0}$ \\
\hline
\end{tabular}

Sumber: Hasil Data Primer, 2017 (Diolah)

Tabel 4 menunjukkan bahwa responden dengan jenis kelamin laki - laki sebanyak 20 responden $(67 \%)$ dan responden dengan jenis kelamin perempuan sebanyak 10 responden $(33 \%)$.

\section{Karakteristik Responden Berdasarkan Usia}

Data responden berdasarkan Umur dapat dilihat pada Tabel 5.

Tabel 5. Karakteristik Responden Berdasarkan Usia

\begin{tabular}{lcc}
\hline Usia & Jumlah & Persentase $(\%)$ \\
\hline$<30$ tahun & 4 & 13 \\
$30-40$ tahun & 26 & 87 \\
\hline Total & $\mathbf{3 0}$ & $\mathbf{1 0 0}$ \\
\hline Sumber: Hasil Data Primer, 2017 (Diolah)
\end{tabular}

Tabel 5 menunjukkan bahwa dapat usia responden paling banyak adalah responden dengan usia antara 30 - 40 tahun yaitu sebesar $87 \%$. Untuk responden yang berusia kurang dari 30 tahun terdapat sebanyak 13\%. Dari data tersebut dapat dikatakan bahwa rata - rata usia kelompok tani di Desa Lembean masih tergolong pada usia produktif.

\section{Karakteristik Responden Berdasarkan Tingkat Pendidikan}

Tingkat pendidikan menentukan cara berpikir seseorang dalam pengambilan keputusan didalam kelompok. Semakin tinggi tingkat pendidikan seseorang maka akan menentukan sikap dan mempengaruhi pengambilan keputusan seseorang. 


\begin{tabular}{lcc} 
Tabel 6. & $\begin{array}{l}\text { Karakteristik } \\
\text { Tingkat Pendidikan Terakhir }\end{array}$ & $\begin{array}{c}\text { Responden } \\
\text { Berdasarkan }\end{array}$ \\
\hline $\begin{array}{l}\text { Tingkat } \\
\text { Terakhir }\end{array}$ & Jumlidikan & $\begin{array}{c}\text { Persentase } \\
(\mathbf{\%})\end{array}$ \\
\hline SD & 2 & 6 \\
SMP & 7 & 24 \\
SMA/SMK & 17 & 56 \\
Sarjana & 4 & 14 \\
\hline Total & $\mathbf{3 0}$ & $\mathbf{1 0 0}$ \\
\hline Sumber: Hasil Data Primer, 2017 (Diolah) &
\end{tabular}

Tabel 6 menunjukkan bahwa tingkat pendidikan sebagian besar kelompok tani di Desa Lembean berpendidikan SMA/SMK sebanyak 17 orang atau $(56 \%)$ dari 30 responden, diikuti dengan pendidikan SMP sebanyak 7 orang atau (24\%), sarjana sebanyak 4 orang atau (14\%), SD sebanyak 2 orang atau (6\%) dari keseluruhan responden.

\section{Penerapan Fungsi Manajemen Kelompok Tani Jagung Lembean}

Hasil penelitian ini menunjukkan bahwa penerapan fungsi manajemen yang diterapkan oleh kelompok tani jagung Lembean berdasarkan kriteria dari fungsi manajemen yaitu perencanaan, pelaksanaan, monitoring, dan evaluasi dengan jumlah skor yang berbeda-beda. Di lihat dari hasil penelitian kelompok tani jagung Lembean bahwa Penerapan Fungsi Manajemen Kelompok Tani Lembean sangat baik, dapat dilihat pada Tabel 7.

Tabel 7. Penerapan Fungsi Manajemen (Perencanaan, Pelaksanaan, Monitoring, dan Evaluasi) Kelompok Tani Jagung Lembean

\begin{tabular}{lcccc}
\hline No & Perencanaan & Pelaksanaan & Monitoring & Evaluasi \\
\hline 1. & 28 & 50 & 24 & 30 \\
2. & 24 & 50 & 4 & 46 \\
3. & 16 & 50 & 30 & 30 \\
4. & 30 & 30 & 30 & 30 \\
5. & 8 & 30 & 30 & 30 \\
\hline Jumlah & $\mathbf{1 0 6}$ & $\mathbf{2 1 0}$ & $\mathbf{1 1 8}$ & $\mathbf{1 6 6}$ \\
\hline
\end{tabular}

Tabel 7 menunjukkan bahwa kelompok tani jagung Lembean telah menerapkan fungsi manajemen dimana jumlah nilai dengan kategor tinggi yang pertama ialah Pelaksanaan dengan jumlah nilai 210, kedua Evaluasi dengan nilai 166, ketiga Monitoring dengan nilai 118, dan Perencanaan dengan nilai 106. Kelompok tani jagung Lembean adalah kelompok tani yang dapat dikatakan berhasil karena telah menerapkan fungsi manajemen dengan skor 3 (Tinggi).

\section{Penerapan Fungsi Manajemen Kelompok Tani Jagung Tumaratak}

Penelitian ini menunjukan tingkatan atau skor yang diperoleh kelompok tani jagung Tumaratak berdasarkan penerapan fungsi manajemen yang terdiri atas kegiatan Perencanaan, Pelaksanaan, Monitoring, dan Evaluasi dengan hasil yang sangat baik dalam penerapan fungsi manajem kelompok tani tumaratak dapat di lihat pada Tabel 8.

Tabel 8. Penerapan Fungsi Manajemen (Perencanaan, Pelaksanaan, Monitoring, dan Evaluasi) Kelompok Tani Jagung Tumaratak

\begin{tabular}{lcccc}
\hline No & Perencanaan & Pelaksanaan & Monitoring & Evaluasi \\
\hline 1. & 36 & 50 & 50 & 30 \\
2. & 30 & 50 & 30 & 50 \\
3. & 5 & 50 & 30 & 30 \\
4. & 30 & 38 & 30 & 50 \\
5. & 30 & 30 & 30 & 50 \\
\hline Jumlah & $\mathbf{1 3 5}$ & $\mathbf{2 1 8}$ & $\mathbf{1 7 0}$ & $\mathbf{2 1 0}$ \\
\hline
\end{tabular}

Tabel 8 menunjukkan bahwa hasil penerapan fungsi manajemen dari kelompok tani jagung Tumaratak dengan jumlah nilai yang diperoleh berbeda-beda. Penerapan fungsi manajemen kelompok tani jagung Tumaratak dikategori tinggi dimana Pelaksanaan dengan jumlah nilai 218, Evaluasi dengan nilai 210, Monitoring dengan nilai 170, dan Perencanaan dengan jumlah nilai 135 . Kelompok tani jagung Tumaratak dapat dikatakan berhasil karena dapat mencapai skor 3 (Tinggi).

\section{Penerapan Fungsi Manajemen Kelompok Tani Jagung Waleposan}

Penelitian terhadap kelompok tani jagung Waleposan mengenai bagaimana penerapan fungsi manajemen terhadap kelompok tersebut. Penerapan fungsi manajemen perencanaan, pelaksanaan, monitoring dan evaluasi dilakukan dengan baik dapat dilihat pada Tabel 9.

Tabel 9. Penerapan Fungsi Manajemen (Perencanaan, Pelaksanaan, Monitoring, dan Evaluasi) Kelompok Tani Jagung Waleposan

\begin{tabular}{lcccc}
\hline No & Perencanaan & Pelaksanaan & Monitoring & Evaluasi \\
\hline 1. & 30 & 50 & 18 & 30 \\
2. & 30 & 50 & 30 & 50 \\
3. & 10 & 50 & 7 & 30 \\
4. & 26 & 30 & 30 & 50 \\
5. & 16 & 50 & 30 & 50 \\
\hline Jumlah & 112 & 230 & 115 & 210 \\
\hline
\end{tabular}


Tabel 9 menunjukkan bahwa hasil dari penerapan fungsi manajemen yang diterapkan oleh kelompok tani jagung Waleposan menunujukan jumlah tingkatan dan skor yang berbeda-beda. Kelompok tani jagung Waleposan dapat dikategorikan tinggi karena penerapan fungsi manajemen yaitu Pelaksanaan dengan nilai 230, Evaluasi dengan nilai 210, Monitoring dengan nilai 115, dan Perencanaan dengan nilai 112. Maka dari itu kelompok tani jagung Waleposan dapat dikatakan berhasil karena telah menerapakan fungsi manajemen dengan jumlah skor 3 (Tinggi).

\section{Karakteristik Kelompok Tani Jagung Di Desa Lembean}

Nama : kelompok tani Lembean

Nama petani : Jefry Lengkong Tuwaida

Ketua

Telly Golioth

Sekretaris

Julita Kalalo

Bendahara

Berdiri tahun : 2013 - sekarang

Fasilitas : mesin bajak lahan, kerbau, rumah penampung,alat pengakut

Bantua : bibi, pupk, lahan, dana, dana

Kelas : pemula

Nama : kelompok tani Tumeratak

Nama petani : Ferly Moningka

Ketua

Donald E. Kaeng

Sekretaris

Sri Sulistiyaningsih

Bendahara

Berdiri tahun : 2015 - sekarang

Fasilitas : kerbau,mesin bajak sewaan

Bantua : bibit, pupuk, lahan, , dana

Kelas : pemula

Nama : kelompok tani waleposan

Nama petani : Ricky A. Sumampouw

Ketua

Jaime Rumampuk

Sekretaris

Arthur Lasut

Bendahara

Berdiri tahun : 2016

Fasilitas : kerbau sewaan, mesin bajak

Bantua : bibit, pupuk, tenaga kerja,dana

Kelas : pemula

\section{KESIMPULAN DAN SARAN}

\section{Kesimpulan}

Penerapan Fungsi Manajemen Pada Kelompok Tani Jagung di Desa Lembean Kecamatan Kauditan, dengan fungsi manajemen yang di ukur dan diperoleh dalam kelompok tani jagung Lembean, kelompok tani jagung Tumaratak dan kelompok tani jagung Waleposan Penerapan Fungsi Manajemen pada Pelaksanaan dan Evaluasi dengan baik dalam penelitian ini pada kategori sangat tinggi sedangkan untuk penerapan Fungsi Manajemen Perencanaan dan Fungsi Manajemen Monitoring ada pada kategori tinggi, pada ketiga kelompok tani jagung di Desa Lembean.

\section{Saran}

Berdasarkan perolehan hasil data yang menunjukan Pemerapan Fungsi Manajemen Kelompok Tani Jagung di Desa Lembean, maka disarankan agar kelompok tani Lembean,kelompok tani Tumaratak dan kelompok tani Waleposan tetap terus mempertahankan bahkan meningkatkan hasil dengan meningkatkan Perencanaan, Pelaksanaan, Monitoring, dan Evaluasi, mempertahankan bahkan meningkatkan komitmen tersirat kepada kelompok tani, mencintai pekerjaan yang dimiliki serta memiliki tujuan kedepan dalam melaksanakan pekerjaan. Untuk memperkuat kerja sama antara kelompok tani jagung, anggota kelompok tani lebih melibatkan diri dalam aktifitas diskusi tentang pekerjaan diluar jam pekejaan, serta saling menolong satu sama lain. Diharapkan aktifitas diskusi ini terjadi bukan hanya sesama kelompok tani tapi juga kelompok tani yang lain dan pemerintah. Penerapan Fungsi Manajemen Kelompok Tani Jagung di Desa Lembean sangat baik dalam melaksanakan kegiatan kelompok tani dengan mengunakan Perencanaan, Pelaksanaan, Monitoring, Dan Evaluasi dengan ini kelompok tani jagung dapat meningkatkan hasil pertanian kelompok tani di Desa Lembean. 


\section{DAFTAR PUSTAKA}

Aak. 1993. Teknik Bercocok Tanam Jagung. Penerbit Kanisius. Jakarta.

Azisturindra's blog pengertian 2 kel tani, 2009. http:// azisturindra .wordpress. com/2009/12/02/ pengertian pengertiankelompok tani / diakses. tanggal 5 Desember 2009 blogspot.com /2012/01/ fungsimanajemen-menurut-henry- fayol-

koleksi.org/ fungsi manajemen-menuruthenry-fayol

Danarti dan S. Najiyati. 1992. Palawija. Penebar Swadaya. Jakarta.

Dinas Pertanian Tanaman Pangan Provinsi Kalimantan Timur. 2002. Petunjuk Pengembangan,

Bimbingan Penyuluhan dan Kelembagaan Kelompok Tani, Samarinda.

Dinas Pertanian Tanaman Pangan Dati I kal-sel, 1999. Petunjuk Teknis Pembinaan Kelem-bagaan dan Pemberdayaan Kelompok , Banjarbaru

George R. Terry \& Leslie W. Rue. (2009). Dasar-Dasar Manajemen. (G.A.Ticoalu, Penerjemah). Jakarta: Bumi Aksara.

Kartasapoetra, A.G. 1994. Teknologi penyuluhan pertanian. Bumi Aksara, Jakarta.

Mardikanto, 1993. Penyuluhan Pembangunan Pertanian. UNS Press .Surakarta

Mardikanto, T, 2009. Sistem Penyuluhan Pertanian. Universitas Sebelas Maret.Surakarta
Mariani. 2012. Manajemen Kelompok Tani Petani Sayuran Dalam Mendukung Kesehatan Pangan Kota Banjar Baru. Jurnal Fakultas Pertanian Universitas Lambung Mangkurat. Manajemen jilid 1/James A.F. Stoner; alih bahasa Alfonsus Sirait Author: Stoner, James A.F.1996

Muhadjir, F. 1986. Jagung. Balai PenelitianTanaman Pangan. Bogor.

Nickels William G., McHugh James M., McHugh Susan M. 1997. Understanding Business. 4th Edition. USA: McGraw Hill Comp. Inc

Sadono Sukirno. 2008.Mikroekonomi: Teori Pengantar. Edisi Ketiga. Jakarta:PT Raja Grafindo Persada

Setiana. L. 2005. Teknik Penyuluhan Dan Pemberdayaan Masyarakat Bogor: Ghalia Indonesia.

Suprapto, H. S. 1990. Bertanam Jagung. Penebar Swadaya. Jakarta.

Suhardiyono, (1992). Penyuluhan petunjuk bagi penyuluhan pertanian. Erlangga. Jakarta.

Suprapto, \& Marzuki. 2005. Botani Tanaman Jagung. Sumatera Utara: Universitas Sumatera Utara Press.

Ridhotullah, Subeki dan Jauhar, Mohammad. (2015). Pengantar Manajemen. Jakarta: Prestasi Pustakaraya.

Rukmana, R.d 1997. Usaha Tanaman Jagung. Kanisius. Yogyakarta. 